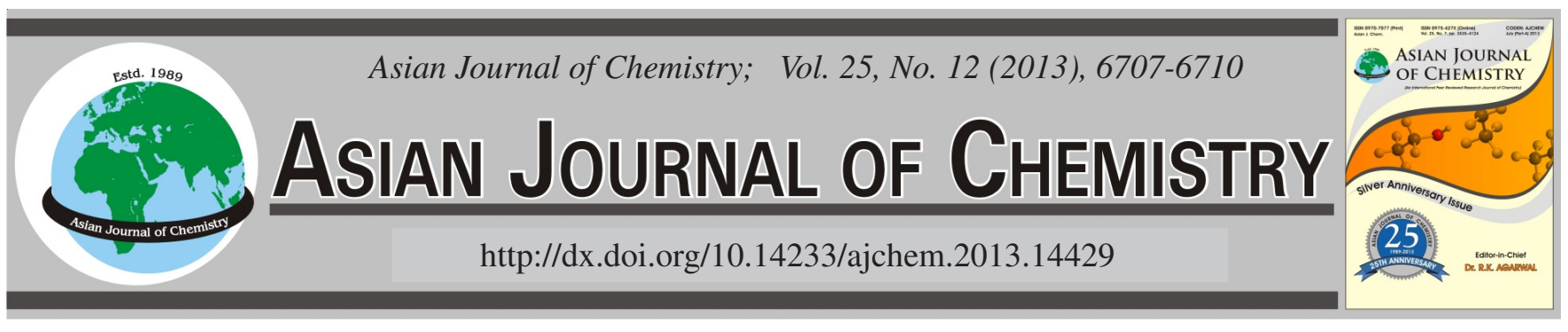

\title{
Rapid HPLC Method to Evaluate the Effect of Herbal Cream on Collagen Content of Skin Tissues Submitted to UV-B Radiation
}

\author{
Arun K. Mishra ${ }^{1, *}$, Amrita Mishra $^{1}$, Anurag Verma $^{1}$ and Pronobesh Chattopadhyay ${ }^{2}$
}

${ }^{1}$ Central Facility of Instrumentation, School of Pharmaceutical Sciences, IFTM University, Moradabad-244 001, India

${ }^{2}$ Pharmaceutical Technology Divison, Defense Research Laboratory, Defence Research and Development Organisation, Tezpur-784 001, India

*Corresponding author: E-mail: arun_azam@rediffmail.com

(Received: 9 August 2012;

Accepted: 27 May 2013)

AJC-13554

\begin{abstract}
For collagen content estimation, from skin tissue of albino rats $(n=6)$, treated with Calendula essential oil based cream and irradiated with UV-B rays $\left(500 \mathrm{~mJ} / \mathrm{cm}^{2}, 12 \mathrm{~min} /\right.$ day for one month), a simple and rapid high-performance liquid chromatographic method using $\mathrm{C}_{18}$ column and hydroxyproline as marker, was developed. The mobile phase consist of acetonitrile and $50 \mathrm{mM}$ sodium acetate buffer $\mathrm{pH} 6$ $(15: 85 \mathrm{v} / \mathrm{v})$ and was pumped at $1.0 \mathrm{~mL} / \mathrm{min}$ at $37^{\circ} \mathrm{C}$. Cysteic acid used as an internal standard. The detection was carried out at $355 \mathrm{~nm}$ and the calibration curve was linear in the range of $10-100 \mu \mathrm{g} / \mathrm{mL}$. The retention time of hydroxyproline was found to be $5.2 \mathrm{~min}$ with a total run time of $10 \mathrm{~min}$. The limit of detection was $0.081 \mu \mathrm{g} / \mathrm{mL}$ and mean recovery was $98 \%$ and $101 \%$. The intraday and interday variation was found to be less than $2 \%$ showing high precision of the assay method. This method is rapid as the total run time is short compared to the run time of $17-30 \mathrm{~min}$ as reported by earlier workers. Therefore, the present method constitute a rapid and accurate diagnostic technique used for detection of hydroxyproline from UV-B irradiated skin tissue.
\end{abstract}

Key Words: Herbal Cream, Hydroxyproline, UV-B Radiation, Skin tissue.

\section{INTRODUCTION}

The skin is an ever-changing organ that contains many specialized cells and structures. Skin is composed of layers, out of which, epidermis layer acts as a barrier, whereas the part of the skin referred as dermis is sandwiched between the hypodermis layer and epidermis layer (the outermost part of the skin). Occurrence of collagen is throughout the body. 90 $\%$ collagen of the body is of type I which is chiefly found in skin and bone ${ }^{1}$. Type II collagen is found in cartilage and the type III collagen occurs in reticular fibers, commonly found along with type I. Collagen IV is responsible for forming the basement of cell membrane, whereas type V collagen occurs on cell surfaces, hair and placenta ${ }^{2}$. Hydroxyproline (Hyp) is a major component of the collagen protein and it comprises around $13.5 \%$ of its amino acid composition ${ }^{3}$. The basis of hydroxyproline quantification is that total collagen can be assessed by acid hydrolysis of proteins followed by measurement of hydroxyproline content. For this reason, Hyp content has been used as an indicator to determine the collagen content. A series of deleterious biochemical reactions occurs within the skin when it is exposed to an excess of UV-B radiation and this process is termed as photoaging ${ }^{4}$. This results in weakening of mature collagen fibers. Thus, due to collagen degradation, eventually skin losses the ability to repair ${ }^{5}$. UV-B irradiation decreases collagen content and induces wrinkle formation ${ }^{6}$. The use of sunscreen creams as photoprotecting agents for UV-B protection is becoming very popular in this context. Antioxidant topical products (such as ointments, creams and lotions) may help to reduce the risk of wrinkles and protect against UV-B radiation ${ }^{7}$. Herbal formulations rich in phenolic acids, flavonoid and high molecular weight polyphenol are considered as useful in preventing the harmful effects of UV$B$ radiation on the skin ${ }^{8}$. In recent years, herbal formulations have gained considerable attention as beneficial protective agents. The application of skin care topical products incorporated with several herbal components e.g. essential oil of Calendula may be an effective strategy in reducing UV-B generated (reactive oxygen species mediated) photoaging. Use of herbal essential oils to formulate topical formulations may also impart many benefits such as a pleasant aroma, emolliency and improvement in the elasticity of the skin ${ }^{9}$. UV-B radiation produces free radicals in skin tissue and the radical scavenging agents incorporated in sun care formulations reduce free radical levels in the skin tissue as well as inhibits photo aging. Reactive oxygen species cause the breakdown of collagen ${ }^{10}$. The effects of Calendula oil for skin healing were already known by ancient Egyptians as anti-fungal and anti-bacterial 
remedies ${ }^{11}$. Calendula was subjected to extraction for oily content because it is reported for various antioxidant activities, anti-inflammatory activity and protection from burning. Due to flavonoid rich content and UV protective action, the Calendula oil was used as dispersed phase in sunscreen formulation.

A great skin care product, whether it comes in a liquid, gel, lotion, or cream, should contain a potent assortment of stable antioxidants to interrupt free radical damage and keep the collagen content normal. The physical stability, antioxidant activity and photoprotective activity of Calendula oil based cream has been recently evaluated and observed that the formulation may be used to protect the skin cell from UV-B ray's in terms of sun protection factor ${ }^{12-14}$. In our earlier research, it has been proved that the cutaneous application of the essential oil of Calendula in form of $\mathrm{O} / \mathrm{W}$ cream prevents UV-B induced alterations in the level of antioxidants and biochemical enzymes of skin tissue ${ }^{15}$. It is common fact that UV-B radiation causes breakdown of collagen fiber and ultimately the collagen level is reduced ${ }^{16}$. This was assumed that Calendula oil based cream may cause reversal of this condition. Keeping in view this fact, the collagen content level was estimated and assumed that if the formulations were found potent in enhancing the collagen level, the Calendula based cream may also be used to combat UV-B rays, wrinkles (the sign of aging) as well as to gain the elasticity of skin. Estimation of the collagen content from skin tissues have been performed by the measurements of the hydroxyproline (Hyp) concentration. Earlier reported colourimetric methods for Hyp determination involved oxidation of hydroxyproline followed by colourimetric reaction with Ehrlich's reagent ${ }^{17}$. In such methods, it is possible that many tissue components can interfere with these reagents, therefore different modifications in the original method were made. These modifications included ion exchange reactions with resins ${ }^{18}$. While some of the reported chromatographic methods require precolumn derivatization by phenyl isothiocynate (PITC), 4-chloro-7-nitrobenzofurazan and reaction with dabsyl chloride and further modification by orthophthalaldehyde which is performed to remove interfering peaks ${ }^{19-21}$. The earlier reported methods for estimation of Hyp contents required a tedious derivatization process as well as long run time ${ }^{22,23}$. We performed simple precolumn derivatization by $N, N$-diethyl-2,4-dinitro-5-fluroaniline (FDNDEA) and liquid chromatography for Hyp quantification as a measure of collagen content from skin samples. Our purpose was to obtain a simple and rapid liquid chromatography method for determination of Collagen content using Hyp as a marker compound from skin tissue. The present novel method utilizes a reverse-phase separation of Hyp as a $N, N$ diethyl-2,4-dinitro-5-fluroaniline (FDNDEA) derivative as well as separation within $10 \mathrm{~min}$ run time. The present method for Hyp estimation is simple, precise and accurate as well as requiring simple precolumn derivatization steps. The developed method requires run time of $10 \mathrm{~min}$ per sample which indicates the main novelty of the method. Thus in comparison to other chromatographic method where a long run time is prohibitive for a large number of samples ${ }^{22}$, the present method may be suitable in these cases.
EXPERIMENTAL

The required chemicals in the study as stearyl alcohol, polysorbate 80 , sorbitan monooletae, sorbitol, methyl paraben and propyl paraben and other chemicals were purchased of LR grade from Central Drug House (CDH), New Delhi. HPLC grade solvents as Water, Methanol, Acetonitrile and triethyamine were purchased from Merck Ltd., Mumbai and Qualigens Fine chemicals, Mumbai. N,N-diethyl-2,4-dinitro5-fluroaniline (FDNDEA) and standard 4-hydroxyproline and L-cysteic acid was purchased from (Sigma Chemical Co. St. Louis, USA).

Extraction of Calendula oil: Calendula flowers were collected from garden of IFTM campus, Moradabad in the month of January 2010 and duly authenticated. A voucher specimen of flowers (No. IFTM/CO/1/2010) is kept in herbarium section of Pharmacy Department, IFTM University, Moradabad, India for future reference. The collected flowers were properly washed with water, segregated in small pieces (total weight $1 \mathrm{Kg}$ ) and packed in the distillation flask of Clavenger's apparatus with sufficient quantity of water and few pieces of porcelain chips to avoid bumping. The extraction was continued for $8 \mathrm{~h}$. The Calendula oil was collected from graduated receiver and purified by anhydrous sodium sulphate for removing water traces.

Formulations: Three optimized stable cream (O/W) formulations were prepared as per our earlier reported formula ${ }^{14}$. The creams were prepared using the concentration of Calendula oil 3, 4 and $5 \%$ (w/w).

Animal study: In this study, 30 albino rats (Wistar strain) were used (body weight 180-225 g). The animals were kept in well ventilated area for the period of experiment till 1 month. The animals were housed in polypropylene cages, placed in climate controlled institutional animal house having temperature $27 \pm 2{ }^{\circ} \mathrm{C}$, relative humidity $65 \pm 2 \%$. Standard laboratory diet ad libitum and drinking water was served to the animals. The animals were kept in animal house as per requirement of CPCSEA (Committee for the purpose of control and supervision of experiments on animals) and approved by the IAEC (Institutional animal ethical committee). To evaluate the effect of herbal cream on collagen content of skin tissues submitted to UVB radiation five groups $(n=6)$ in each were divided in following manner.

Group 1. Without UV-B irradiation and without cream treatment Group 2. UV-B irradiated

Group 3. UV-B irradiated + F3 treated Group 4. UV-B irradiated + F4 treated Group 5. UV-B irradiated + F5 treated

Experimental doses of UV-B radiation on skin cells of rats was $500 \mathrm{~mJ} / \mathrm{cm}^{2}$ with an exposure time $12 \mathrm{~min}$ per day (daily) for 1 month. The formulations were applied daily 30 min before UV-B irradiation. Prior to irradiation, $2.5 \mathrm{mg} \mathrm{cm}^{-2}$ of the test samples were applied to hairless skin of $\mathrm{Gr} 3,4$ and Gr 5 animals. To cause irradiation on skin surface of albino rats, ultraviolet range lamps (Toshiba light Co.) previously calibrated were used. The emission peak was $298 \mathrm{~nm}$ and the spectral output was in the range $290-310 \mathrm{~nm}$. The dose of radiation exposure $\left(\mathrm{mJ} / \mathrm{cm}^{-2}\right)$ was calculated from irradiance $\left(\mathrm{mW} \mathrm{cm} \mathrm{cm}^{-2}\right) \mathrm{X}$ time of exposure (min). Time of exposure was 
calculated as per OECD guidelines. A UV dose increment for each case was $25 \%$ and the total test area was $16 \mathrm{~cm}^{2}$. The formulation quantity was weighed and evenly applied to the skin. The time between application of the formulation and irradiation was $30 \mathrm{~min}$. After 30 days study, rats were sacrificed. The shaved dorsal skin samples were carefully dissected free. Tissue specimens from the back of the skin for all the groups were thoroughly rinsed using physiological saline, diluted ten times with distilled water and stored at $-70{ }^{\circ} \mathrm{C}$ in deep freezer. One gram skin tissue sample was weighed from each group and frozen tissue samples were minced on glass plate over ice bags and then homogenized. The tissue homogenate were centrifuged (Microcentrifuge-Remi Co.) at 8000 rpm for $10 \mathrm{~min}$ and supernatant liquid was stored in the deep freezer zone $\left(-80^{\circ} \mathrm{C}\right)$ till the start of collagen estimation by chromatography study.

Reagents and solutions: A stock solution of hydroxyproline $(1 \mathrm{mg} / \mathrm{mL})$ was prepared in $\mathrm{HCl}$. Aliquots of concentration $10,20,30,40,50,60,70,80,90$ and $100 \mu \mathrm{g} / \mathrm{mL}$ of working standard solution of Hyp were prepared in HPLC grade water and kept on $-20{ }^{\circ} \mathrm{C}$ until use. Freshly prepared sodium hydrogen carbonate $(2 \mathrm{~mol} / \mathrm{L}, \mathrm{pH} 9.3)$ was used in preparing Cysteic acid $(50 \mu \mathrm{g} / \mathrm{mL})$ as internal standard, stored at $-20^{\circ} \mathrm{C}$ until use. FDNDEA $(1 \mathrm{mg} / \mathrm{mL})$ was prepared in acetonitrile in a dark environment and kept at $4{ }^{\circ} \mathrm{C}$.

HPLC instrumentation: An isocratic HPLC (Shimadzu Co. Kyoto, Japan) with LC-20 AT pumps (Shimadzu), variable wave length programmable UV detector SPD-20A (Shimadzu), Phenomenex ODS analytical $\mathrm{C}_{18}$ column $(150 \mathrm{~mm} \times 4.6 \mathrm{~mm}$, $5 \mu \mathrm{m}$ particle size), was used. The HPLC system was equipped with HP Compaq computer and software DS-200 series for control of the whole apparatus.

Chromatographic conditions: Chromatographic study of hydroxyproline from skin tissue components was performed isocratically. Mobile phase was a mixture of acetonitrile and $50 \mathrm{mM}$ sodium acetate buffer $\mathrm{pH} 6(15: 85 \mathrm{v} / \mathrm{v})$ and UV detector was set at wavelength maxima $355 \mathrm{~nm}$. Each component was filtered through a $0.45 \mathrm{~nm}$ pore size cellulose nitrate membrane filter paper before HPLC analysis. The flow rate was $1 \mathrm{~mL} /$ min. Three replicates per concentration were injected and chromatograms were recorded. The flow rate was $1 \mathrm{~mL} / \mathrm{min}$ which yielded a column back pressure of $120 \mathrm{kgf} / \mathrm{cm}^{2} .20 \mu \mathrm{L}$ of the sample was injected by using Rheodyne syringe (Model 7202, Hamilton). After the appearance of hydroxyproline peak and completion of $10 \mathrm{~min}$ run time, the next sample was loaded after $5 \mathrm{~min}$.

Precolumn derivatization and sample treatment: The stored skin tissue homogenate (as discussed earlier) was centrifuged at $5000 \mathrm{rpm}$ for $5 \mathrm{~min}$ to remove particulate. 100 $\mu \mathrm{L}$ of supernatant was transferred into a clean borosilicate glass tube. $100 \mu \mathrm{L}$ of HPLC grade water and $200 \mu \mathrm{L}$ of concentrated $\mathrm{HCl}$ was added in this and subjected to hydrolysis for $16 \mathrm{~h}$ at $110^{\circ} \mathrm{C}$ so that bound hydroxyproline may be released. The hydrolyzate was evaporated under reduced pressure and afterward, reconstituted with $400 \mu \mathrm{L}$ of acetone and dried. $500 \mu \mathrm{L}$ of cysteic acid solution was used to reconstitute the residue. $50 \mu \mathrm{L}$ of the resulting solution was added to $50 \mu \mathrm{L}$ of FDNDEA solution and maintained $100^{\circ} \mathrm{C}$ for $20 \mathrm{~min}$ and dried. The DNDEA adduct was redissolved in $500 \mu \mathrm{L}$ of the mobile phase and $20 \mu \mathrm{L}$ of the sample was injected through Rheodyne injector.

Validation studies: To perform the precision study, intraday concentration of hydroxyproline was estimated on the same day at an interval of $1 \mathrm{~h}$ and for interday study; final aliquots were analyzed on three different days. Mean recovery was estimated by analyzing two skin homolysate sample in which 20 and $80 \mu \mathrm{g} / \mathrm{mL}$ sample was added before hydrolysis.

Quantification: After setting the chromatographic conditions and stabilizing the instrument to obtain a steady baseline, the sample solution was injected, chromatogram was obtained and the peak areas were recorded. For this, aliquots of concentration 10, 20, 30, 40, 50, 60, 70, 80, 90 and $100 \mu \mathrm{g} /$ $\mathrm{mL}$ of standard solutions of hydroxyproline were derivatized as above. The peak area ratios of the hydroxyproline to the internal standard (cysteic acid) were calculated and plotted $v s$. concentration of standard solution. Linear regression analysis was applied. Thus the amount of hydroxyproline in each sample was estimated.

\section{RESULTS AND DISCUSSION}

Chromatographic profile of hydroxyproline: Fig. 1 represents the peaks of DNDEA-hydroxyproline adduct and cysteic acid as an internal standard. In a total run time of 10 min, cysteic acid and Hyp appeared at 3.6 and 5.2 min respectively (Figs. 1 and 2).

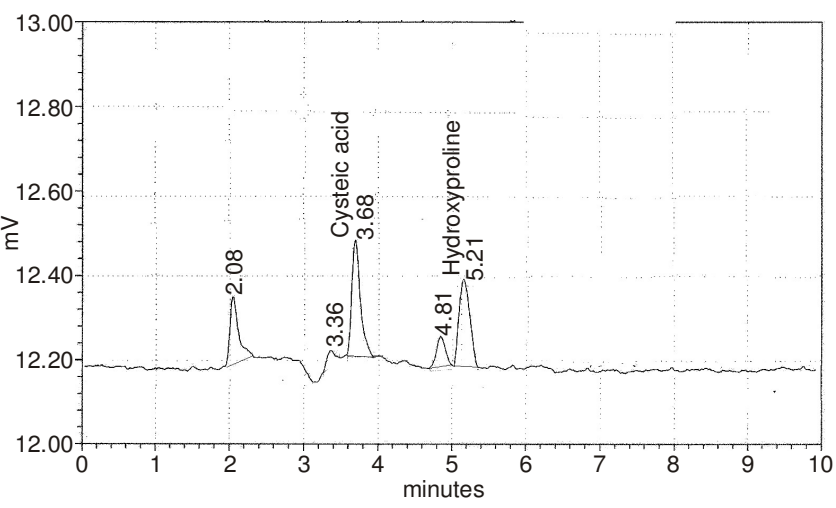

Fig. 1. Chromatogram of DNDEA-Hyp complex and cysteic acid as internal standard in aqueous standard mixture

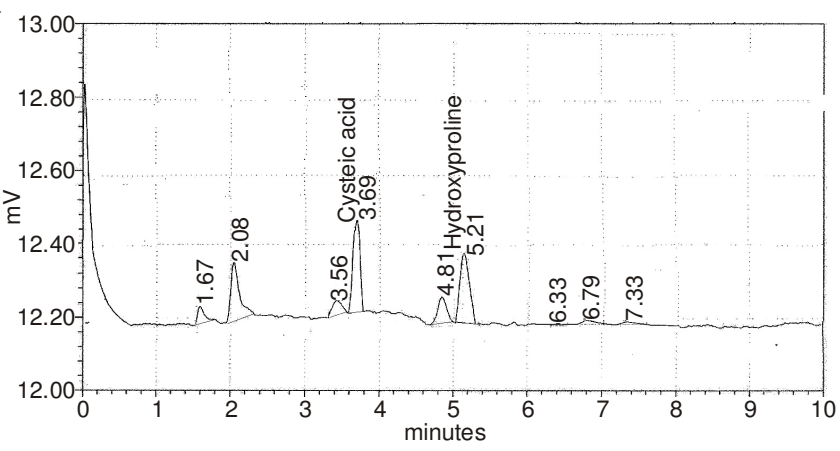

Fig. 2: Chromatograms of DNDEA-Hyp derivatized and cysteic acid from skin tissue homolysate

Linearity and range: The calibration curve showed good linearity in the range of $10-100 \mu \mathrm{g} / \mathrm{mL}$, for hydroxyproline with regression coefficient 0.997 (Table-1). Line equation showed the slope value 42.58 and intercept 17.52 . 
TABLE-1

HPLC METHOD VALIDATION PARAMETERS FOR QUANTIFICATION OF HYDROXYPROLINE

\begin{tabular}{ll}
\hline Parameter & Result \\
\hline Linearity $(\mu \mathrm{g} / \mathrm{mL})$ & $10-100$ \\
Regression coefficient $\left(\mathrm{r}^{2}\right)$ & 0.997 \\
RT $($ min $)$ of Cysteic acid and Hyp & $3.6 \& 5.2$ \\
LOD and LOQ $(\mu \mathrm{g} / \mathrm{mL})$ & $0.081 \& 0.257$ \\
Intraday precision $(50 \mu \mathrm{g} / \mathrm{mL})(\mathrm{n}=3, \% \mathrm{RSD})$ & 1.55 \\
Interday precision $(50 \mu \mathrm{g} / \mathrm{mL})(\mathrm{n}=3, \% \mathrm{RSD})$ & 1.12 \\
Recovery $(20 \mu \mathrm{g} / \mathrm{mL}$ and $80 \mu \mathrm{g} / \mathrm{mL})(\mathrm{n}=3)$ & $98 \%$ and $101 \%$ \\
\hline
\end{tabular}

LOD and LOQ: The minimum concentration at which the analyte can be detected corrected is limit of detection (LOD) and is quantified (LOQ) were found to be 0.081 and $0.257 \mu \mathrm{g} / \mathrm{mL}$ respectively.

Intra-day assay and inter-day assay: The intra and inter day variation of the proposed method for $50 \mu \mathrm{g} / \mathrm{mL}$ was carried out in triplicate. Using mean value and standard deviation, percentage relative standard deviation $(\%$ RSD $<2 \%)$ was calculated. In our case, intraday precision and interday precision for Hyp were 1.55 and 1.12, respectively which showed that the proposed method is precise.

Recovery study: Recovery studies were carried out by adding $100 \%$ amount of Hyp to the preanalyzed samples of concentration $20 \mu \mathrm{g} / \mathrm{mL}$ and $80 \mu \mathrm{g} / \mathrm{mL}$. The process was repeated in triplicate. From this, percentage recovery was calculated. The outcome of recovery studies indicates the accuracy of the method.

The regression coefficient was 0.997 . The results of the limit of detection, limit of quantification, precission (intraday and interday) and recovery studies are presented in Table-1. The concentrations of Hyp $(\mu \mathrm{g} / \mathrm{g})$ in skin tissue for the group 1 to Gr 5 animals were calculated and are presented in Table2. The concentration of Hyp observed in case of Gr 5 was highest among all groups indicating increased amount of collagen after treatment with F5 formulation. The Hyp level of Gr1 animals $(52.252 \pm 0.526 \mu \mathrm{g} / \mathrm{g})$ was more when compared with Gr 2, 3 and Gr 4 animals. It was because of non irradiated skins of Gr 1 animals. Gr 2 was irradiated with UV-B rays and the Hyp level was least in this. It may be because of the collagen damaging effect of UV-B radiation. The concentration of Hyp was increased from Gr 2 to 4 . As UV-B radiation can cause breakdown of collagen and results in decreased amounts of Hyp but the treatment of F3, F4 and F5 reversed the condition. It was because of the protective effect of formulations. The animals treated with F5 formulations were having maximum collagen content probably because of incorporation of $5 \%$ Calendula oil.

TABLE-2

CONCENTRATION OF Hyp $(\mu \mathrm{g} / \mathrm{g})$ IN SKIN TISSUES SUBMITTED TO UV-B RADIATION

Animal group $(\mathrm{n}=6)$

Gr 1

Conc. of Hyp $(\mu \mathrm{g} / \mathrm{g})$

Gr 2

$52.252 \pm 0.526$

$15.956 \pm 0.562$

Gr 3

$29.121 \pm 0.411$

Gr 4

$49.841 \pm 0.712$

Gr 5

$63.414 \pm 0.227$

\section{Conclusion}

The proposed method for hydroxyproline (collagen marker) estimation is simple, sensitive and rapid. The method for hydroxyproline estimation by HPLC was developed after more than twenty trials. In each trial, peak symmetry and resolution was improved. The earlier reported methods involve tedious and time consuming steps whereas, in our method, a simple precolumn derivatization step was involved as well as no interference of derivatizing agent was observed during chromatographic analysis. The main novelty of the proposed method is short run time $(10 \mathrm{~min})$. The reproducibility of the method was high. This method may be used to estimate the collagen content of skin tissue as well as other body tissues having collagen. Validation studies of the proposed method indicate a high level of accuracy and precision of this simple and rapid method.

\section{ACKNOWLEDGEMENTS}

The authors are thankful to Prof. (Dr.) R.M. Dubey (Vicechancellor IFTM University, Moradabad) for providing the necessary research facilities.

\section{REFERENCES}

1. J.A. Trotter, K.E. Kadler and D.F. Holmes, J. Molecul. Biol., 300, 531 (2000).

2. L.T. Smith, Matrix Biol., 14, 159 (1994).

3. D.L. Nelson and M.M. Cox, Lehninger's Principles of Biochemistry, W.H. Freeman and Company, New York, edn 4 (2005).

4. M.D. Carbonare and M.A. Pathak, J. Photochem. Photobiol., 14, 105 (1992).

5. D.G. Greenhalgh, Int. J. Biochem. Cell Biol., 30, 1019 (1998).

6. Y. Takema, M. Hattori and K. Aizawa, J. Dermatol. Sci., 12, 56 (1966).

7. P.K. Mukherjee, N. Maity, N.K. Nema and B.K. Sarkar, Phytomed., 19, 64 (2011).

8. G. González, M. Fernández-Lorente and Y. Gilaberte-Calzada, Clinics in Dermatol., 26, 614 (2008).

9. S. Liao, Y.H. Kao and R.A. Hiipakka, Vit. Horm., 62, 11 (2001).

10. J. Fuchs, Free Rad. Biol. Med., 25, 848 (1988).

11. M. Valko, D. Leibfritz, J. Moncol, M.T.D. Cronin, M. Mazur and J. Telser, Int. J. Biochem. Cell Biol., 39, 44 (2007).

12. A.K. Mishra, A. Mishra and P. Chattopadhyay, J. Young. Pharm., 4, 17 (2012).

13. A.K. Mishra, A. Mishra and P. Chattopadhyay, Int. J. Biomed. Res., 5, 201 (2010).

14. A.K. Mishra, A. Mishra and P. Chattopadhyay, Orient. Pharm. Exper. Med., 12, 35 (2012).

15. A.K. Mishra, A. Mishra, A. Verma and P. Chattopadhyay, Sci. Pharm., 80, 669 (2012).

16. A.L. Bulteau, M. Moreau, C. Nizard and B. Friguet, Free Radic. Biol. Med., 32, 1157 (2002).

17. G.R. Kesava and C.S. Enwemeka, Clin. Biochem., 29, 225 (1966).

18. B.C. Goverde and F.J.N. Veenkamp, Clin, Chim. Acta., 41, 29 (1972).

19. P.A. Biondi, L.M. Chiesa and M.R. Storelli, J. Chromatogr. Sci., 35, 509 (1997).

20. M. Ahnoff, I. Grundevik, A. Arfwidsson, F. Fonselius and B.A. Persson, Anal. Chem., 53, 485 (1981).

21. M. Saito, K. Marumo, K. Fujii and N. Ishioka, Anal. Biochem., 253, 26 (1997).

22. P.R. Hutson, M.E. Crawford and R.L. Sorkness, J. Chromatogr. B, 791, 427 (2003).

23. R. Paroni, D. Vecchi, I. Fermo, C. Arcelloni, L. Diomede, F. Magni and P.A. Bonini, Clin. Chem., 38, 407 (1992). 